Sains Malaysiana 48(9)(2019): 2041-2049

http://dx.doi.org/10.17576/jsm-2019-4809-25

\title{
An Enhanced Safrole Sensing Performance of a Polyacrylonitrile Nanofiber-Based-QCM Sensor by Overlaying with Chitosan
}

(Peningkatan Prestasi Mengesan Safrola bagi Poliakrilonitril Nanogentian-Berasaskan Sensor QCM yang Disalut dengan Kitosan)

\author{
Aditya Rianjanu, KuWAT Triyana*, Novalia Nurbaiti, Siti ASTUti HaSANAH, \\ AHMAD KUSUMAATMAJA \& ROTO ROTO
}

\begin{abstract}
We report on a method to enhance the sensing performance of polyacrylonitrile (PAN) nanofiber-based QCM sensor overlaid with chitosan. The PAN nanofibers were deposited on the QCM sensing surface by electrospinning technique followed by overlay with chitosan by a drop-casting method. The Fourier transform infrared (FTIR) spectra confirm that chitosan covers the PAN nanofibers. The SEM images show the average diameter of the produced PAN nanofibers was $236 \mathrm{~nm}$, and it increased to $283 \mathrm{~nm}$ after overlay with chitosan. The modified QCM sensor has the sensitivity of $18.7 \mathrm{~Hz} \mathrm{mg}^{-1} \mathrm{~L}$, which is better than that of PAN nanofiber alone of $4.5 \mathrm{~Hz} \mathrm{mg}^{-1} \mathrm{~L}$. It is an increase nearly 5 times. The analytical parameters of the limit of detection (LOD), sensitivity, a time constant, and stability improved after the PAN nanofiber sensor was overlaid with chitosan. The amine groups present in chitosan interact effectively with safrole, thus increase the sensing response. The proposed device is robust, inexpensive, and convenient for detecting safrole, and can be used as an alternative to those of classical instrumental methods for the analysis of safrole as a drug precursor.
\end{abstract}

Keywords: Chitosan; ecstasy; quartz crystal microbalance; safrole; vapor sensor

ABSTRAK

Kajian ini melaporkan tentang kaedah untuk meningkatkan prestasi pengesanan poliakrilonitril (PAN) berasaskan sensor gentian nano QCM yang disaluti dengan kitosan. PAN nanofiber diendap pada permukaan pengesan QCM oleh teknik putaran elektro diikuti dengan salutan kitosan melalui kaedah drop-pemutus. Spektrum transformasi Fourier inframerah (FTIR) mengesahkan kitosan menutup gentian nano PAN. Imej SEM menunjukkan diameter purata gentian nano PAN yang dihasilkan adalah $236 \mathrm{~nm}$ dan ia meningkat kepada $283 \mathrm{~nm}$ selepas bertindih dengan kitosan. Sensor QCM terubah suai mempunyai kesensitifan $18.7 \mathrm{~L} \mathrm{mg}^{-1} \mathrm{~Hz}$, lebih baik daripada gentian nano PAN sahaja iaitu $4.5 \mathrm{~Hz} \mathrm{mg}^{-1} \mathrm{~L}_{\text {. Ini merupakan }}$ peningkatan hampir 5 kali ganda. Analisis parameter had pengesanan (LOD), kesensitifan, pemalar masa dan kestabilan bertambah baik selepas sensor gentian nano PAN disaluti dengan kitosan. Golongan amina yang hadir dalam kitosan berinteraksi secara berkesan dengan safrola, sekaligus meningkatkan respons pengesanan. Peranti cadangan ini teguh, murah dan mudah untuk mengesan safrola dan boleh digunakan sebagai alternatif kepada metod instrumen klasik untuk menganalisis safrola sebagai pelopor dadah.

Kata kunci: Ekstasi; kitosan; kristal kuarza mikroneraca; safrola; wap sensor

\section{INTRODUCTION}

In recent years, drug abuse has grown rapidly and become one of the major health threats to our society, causing economic and political issues (Hernández et al. 2014; Singer 2008). The smuggling of unlawful drugs has also spread worldwide. Since 2010, the quantity of drugs seized globally has averaged approximately 4-5 tons per year (United Nations Office on Drugs and Crime 2017). The detection of illegal drug precursors remains a problem faced by law enforcement worldwide. Several studies have highlighted the need for the development of a better method for the detection of drug-synthesis reactants (Hackner et al. 2013; Pinalli et al. 2013). Main drug precursors include benzodioxol, benzyl methyl ketone (BMK), and safrole. Safrole is the precursor for the synthesis of the amphetamine-type stimulant (ATS) drug, N-methyl-3,4methylenedioxyamphetamine (MDMA), commonly known as ecstasy.

Conventional methods of analyses such as liquid chromatography (LC), gas chromatography (GC), and liquid chromatography coupled with mass spectrometry (LC-MS) (Honeychurch 2016; Saito et al. 2011) are often employed for forensic safrole testing. However, these methods are costly, not portable, and challenging to operate in real-time applications. Therefore, a rapid, reliable and real-time safrole sensor is needed.

Studies show that the development of real-time sensors for volatile organic compounds (VOCs) is progressing rapidly. These sensors are developed based on unique electrode-analyte interactions such as resistive (Wang et 
al. 2017), photoelectric (Aba et al. 2014), amperometric (He et al. 2014), optical (Evyapan et al. 2016), and acoustic wave interactions (Wang et al. 2015). To obtain sensitive, real-time, and convenient vapor detection, the quartz crystal microbalance (QCM) sensors are developed as a very promising alternative to classical detection methods (Julian et al. 2019; Siow et al. 2019). The quartz crystal microbalance is an acoustic wave sensor platform, based on the acoustic-electric effect and are capable of determining even nanogram-level mass changes. By deposition on an appropriate sensing chip, the microbalance responds to specific analytes via a frequency shift, which results from the mass increase caused by sorption of analytes onto the sensing material, according to the Sauerbrey equations (Sauerbrey 1959). Various sensing materials such as polymers (Hidayat et al. 2017; Rianjanu et al. 2019b), metal oxides (Zhang et al. 2018, 2015), and some functional materials (Lu et al. 2015) have been introduced to modify QCM sensors.

Nanostructured materials, especially nanofibers, have been studied primarily for devices for gas or vapor sensing (Ding et al. 2010; Rianjanu et al. 2019a; Sun et al. 2012). Nanofibrous structured materials have a large specific surface area, high porosity, and interconnected porous structures (Chotimah et al. 2016; Mahendra et al. 2018; Rianjanu et al. 2018c), which are advantageous for the development of gas or vapor sensing devices. A gas sensor prepared by nanostructured materials has an increased sensitivity due to the larger specific surface areas of the materials (Jia et al. 2017, 2014). We have reported earlier on a nanofiber-based QCM safrole sensor (Rianjanu et al. 2018a). However, the sensitivity was not satisfactory. There have been several nanofiber modification methods proposed to increase the sensitivity of nanofibrous sensors, including the construction of a nanofibers-net-binary (NNB) structure (Wang et al.2014) and the functionalization of the nanofiber (Huang et al. 2013; Jia et al. 2016). The increase in the specific area and chemical functionalization of the QCM sensing chip improves both selectivity and sensitivity.

Electrospun polyacrylonitrile (PAN) nanofibers are mechanically stable, water-insoluble, and hydrophobic, which makes them good candidates for QCM sensing chip modification (Rianjanu et al. 2018b, 2018d). The development of PAN nanofiber as safrole sensor has been done previously (Rianjanu et al. 2018a). Although the methods are easy to use and inexpensive, the sensitivity was insufficient. To increases its sensitivity, we used chitosan to overlay its surface to exploit its amine group. Chitosan (Cs) is a natural polymer which consists of a polysaccharide containing the functional groups $-\mathrm{OH}$ and $-\mathrm{NH}_{2}$ and possesses many promising properties such as excellent filmforming ability, high mechanical strength, biodegradability, biocompatibility and antibacterial properties (Ayad et al. 2014). Considerable efforts have been devoted to devising gas/vapor sensors using chitosan and its composites as active layers (Ayad \& Minisy 2016; Triyana et al. 2018; Zhang et al. 2017). However, to the best of our knowledge, there has been no effort to develop a promising strategy to modify PAN nanofibers with chitosan and combine these with QCM to construct sensitive safrole sensors.

In this work, we aim to improve the PAN nanofiberbased QCM safrole sensor performance by overlay with chitosan. PAN/Cs nanofibrous membranes' large surface areas, high porosity, and rigidity of PAN, along with the presence of amine groups in the chitosan structure, cause the QCM sensing chip to exhibit better performance in terms of fast response, reproducibility, and sensitivity, which is promising for routine safrole detection at room temperature.

\section{MATERIALS AND METHODS}

\section{MATERIALS}

Polyacrylonitrile $\left(\mathrm{M}_{\mathrm{w}}=150,000 \mathrm{~g} / \mathrm{mol}\right)$ and chitosan $\left(M_{w}=190,000-310,000 \mathrm{~g} / \mathrm{mol}\right)$ were supplied by Sigma-Aldrich. The nonionic surfactant Triton X-100, $\mathrm{N}, \mathrm{N}$-dimethylformamide (DMF), formaldehyde, acetone, ethanol, $\mathrm{H}_{2} \mathrm{O}, 1$-propanol, benzene, toluene, xylene, and acetic acid were purchased from Merck, Germany. Safrole with $96 \%$ purity, used as the main analyte, was provided officially by The Indonesian National Police, Jakarta. The AT-Cut QCM sensors with gold $(\mathrm{Au})$ electrodes and $10 \mathrm{MHz}$ base resonant frequency were purchased from OpenQCM, Novaetech, Italy. All chemicals were used without any further purification.

\section{NANOFIBER PREPARATIONS}

Polyacrylonitrile (PAN) nanofibers were prepared by an electrospinning technique, using conditions similar to those of our previous study (Rianjanu et al. 2018a). After the PAN nanofibers were successfully deposited on to the QCM surface, the nanofibers were modified with chitosan by a drop-casting method. The chitosan solution was prepared by dissolving $1.05 \mathrm{~g}$ chitosan powder into $10 \mathrm{~mL}$ of an aqueous solution of $2 \mathrm{wt}$. \% acetic acid, followed by mechanical stirring at $1000 \mathrm{rpm}$ for $2 \mathrm{~h}$. The $0.01 \mathrm{wt}$. $\%$ chitosan solution was made via the dilution of the concentrated solution. The preparation of the PAN nanofiber overlay with chitosan was prepared as the following. Five microliter chitosan solution (0.01 wt. \%) dropped-cast onto the QCM, which has been initially covered with PAN nanofibers, by using a micropipette to give the chitosanmodified PAN nanofiber QCM chip. After the solvent was completely evaporated at room temperature, the QCM chips were dried in the air overnight. For convenience PAN nanofiber overlay with chitosan called PAN/Cs nanofiber hereafter.

The morphology of the nanofibers was analyzed using a scanning electron microscope (SEM, JEOL JSM-6510). The FTIR spectra were collected on an FTIR spectrophotometer (8201PC, Shimadzu). The schematic illustration of the sensor fabrication with the chemical structures of all used materials is shown in Figure 1. 


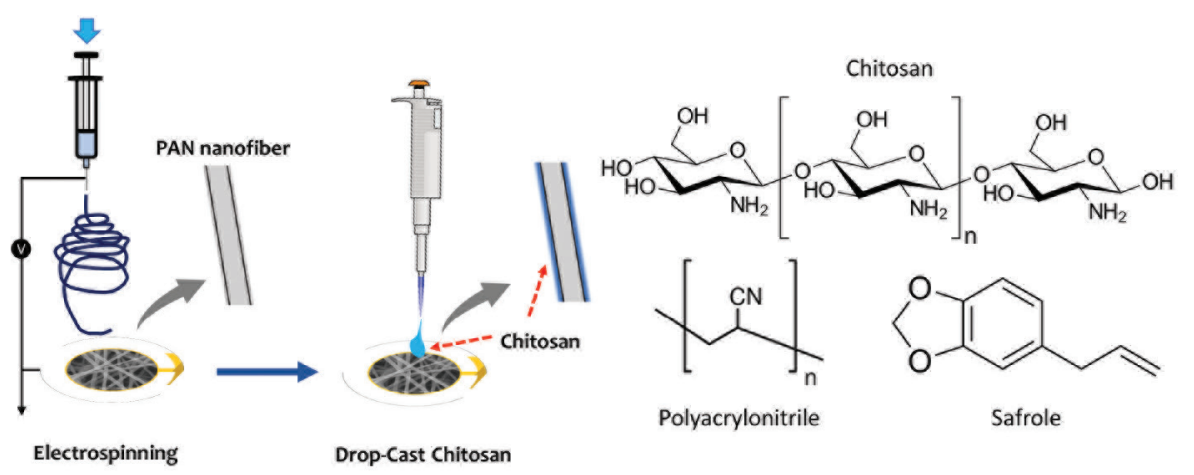

FIGURE 1. Schematic illustration and chemical structure of PAN nanofiber modified with chitosan deposited on the QCM surface

\section{SAFROLE SENSOR CONFIGURATION AND EXPERIMENTAL SETUP}

The schematic diagram for safrole vapor analysis by the batch system is available in our previous work (Rianjanu et al. 2018a; Triyana et al. 2018). The QCM sensor was installed in the testing chamber with a volume of $1.25 \mathrm{~L}$. The measurement was taken place at an ambient condition. The temperature and the relative humidity inside the chamber were monitored by a calibrated sensor of Sensirion SHT-31. Two types of microliter syringes (10- $\mu \mathrm{L}$, Hamilton Model 701 RN SYR, and 1- $\mu \mathrm{L}$, Hamilton Model 7001KH SYR) were used for analyte injection. The concentration of the injected analyte in the chamber was expressed in $\mathrm{mg} \cdot \mathrm{L}^{-1}$ and calculated using density, percent purity, and volume of analytes. The responses of the QCM sensors were examined by measuring the change in the resonance frequency, as measured by a frequency counter. The change in the resonant frequency of the QCM sensor is related to the change in mass loading on the QCM sensor chip. The frequency change data were recorded with a PC equipped with the LabVIEW graphical programing language. To desorb the analyte vapor from the QCM sensing chips, the dry ambient air was used for purging. The frequency shift of the QCM before and after coating with PAN nanofibers was approximately $1800 \mathrm{~Hz}$. Moreover, after chitosan drop-casting and drying, an additional frequency shift of $1500 \mathrm{~Hz}$ was observed. This frequency shift represented the coating on top of the QCM substrate.

\section{RESULTS AND DISCUSSION \\ NANOFIBER MORPHOLOGY}

Figure 2 shows the microscopic view of the PAN nanofiber and PAN/Cs nanofiber at different magnifications. The electrospun PAN nanofibers exhibit randomly oriented three-dimensional (3D) porous structures, with a diameter of approximately $236 \pm 46 \mathrm{~nm}$. After chitosan drop-casting and drying (PAN/Cs nanofiber), the nanofiber diameter increased slightly, to $284 \pm 29 \mathrm{~nm}$. It indicates that chitosan covers the PAN nanofiber surface. It also confirms that
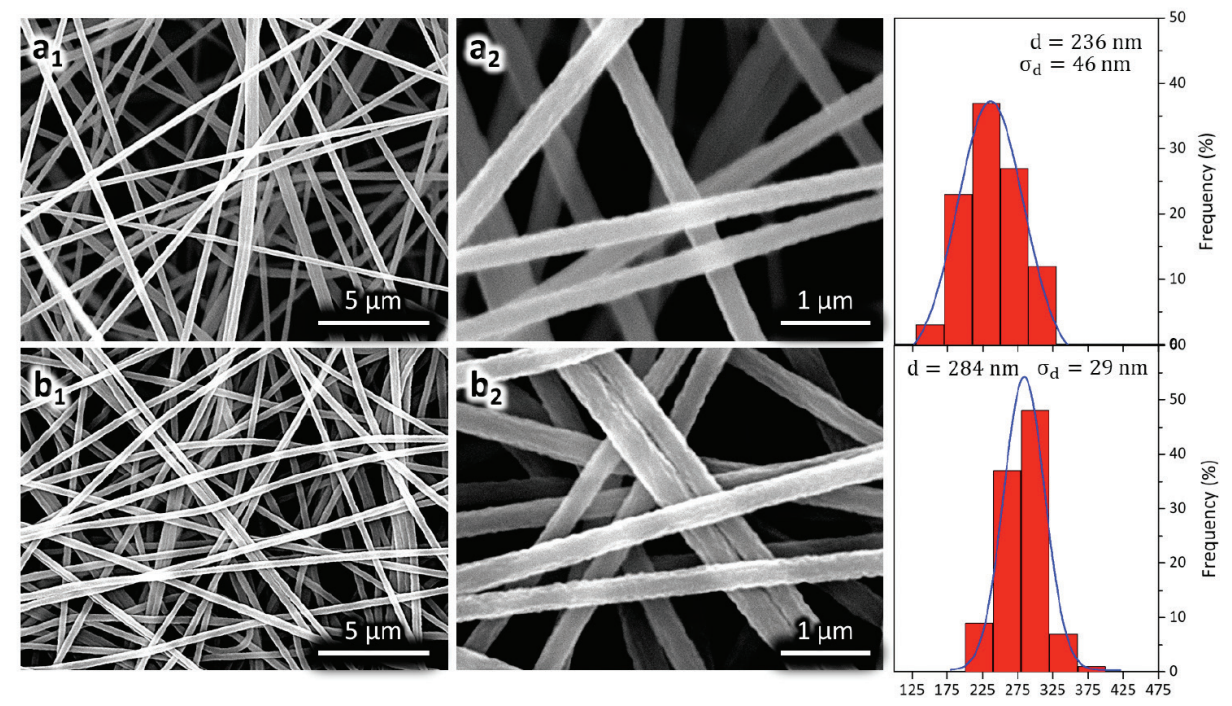

Nanofiber diameter (nm)

FIGURE 2. SEM images of PAN nanofiber $\left(a_{1}\right.$ and $\left.a_{2}\right)$, and PAN/Cs nanofiber $\left(b_{1}\right.$ dan $\left.b_{2}\right)$ at different magnifications with its nanofiber diameter distribution 
the 3D structure of the sensor remains unchanged after modification, where the surface of the sensor is covered with chitosan.

\section{FTIR ANALYSIS}

The FTIR spectra of chitosan powder, PAN nanofiber, and PAN/Cs nanofiber are shown in Figure 3. The sharp bands at $2931 \mathrm{~cm}^{-1}$ and $2877 \mathrm{~cm}^{-1}$ can be attributed to stretching vibrations of ethylene, $\mathrm{CH}_{2}$, while that at $2245 \mathrm{~cm}^{-1}$ is due to the stretching of $\mathrm{C} \equiv \mathrm{N}$. Moreover, the peaks at 1450,1357 , and $1249 \mathrm{~cm}^{-1}$, respectively, correspond to the bending vibrations of various aliphatic $\mathrm{C}-\mathrm{H}$ groups $\left(\mathrm{CH}, \mathrm{CH}_{2}\right.$, and $\mathrm{CH}_{3}$, respectively). A weak peak at 1620 $\mathrm{cm}^{-1}$ could be assigned to amide groups (Cipriani et al. 2016; Li et al. 2013). Also, the band observed near 1110 $\mathrm{cm}^{-1}$ is possibly due to the $\mathrm{C}-\mathrm{H}$ rocking mode of $\mathrm{CH}_{3}$ groups of any residual DMF solvent (Portaccio et al. 2015). The peak that appeared at $1620 \mathrm{~cm}^{-1}$ is likely due to the O-H bending of chitosan (Kakida \& Tashiro 1997; Xue et al. 2013).

The strong, broadband observed at $3425 \mathrm{~cm}^{-1}$ can be attributed to the stretching vibrations of $\mathrm{O}-\mathrm{H}$ and $\mathrm{N}-\mathrm{H}$ groups. The peaks are seen at $2924 \mathrm{~cm}^{-1}$ and $2877 \mathrm{~cm}^{-1}$ could be assigned to the $\mathrm{C}_{\mathrm{sp} 3}-\mathrm{H}$ stretching of the ethylene groups of chitosan. The peak detected at $1651 \mathrm{~cm}^{-1}$ may be attributed to the $\mathrm{C}=\mathrm{O}$ stretching of the amide groups of chitosan. The peak at $1581 \mathrm{~cm}^{-1}$ is due to the $\mathrm{N}-\mathrm{H}$ bending of chitosan's primary amine. Other peaks of chitosan in the fingerprint area are also observed (Ayad et al. 2014; Kim \& Lee 2014).

The FTIR spectrum of PAN/Cs nanofibers shows the characteristic peaks of both PAN and chitosan. The peaks observed in the PAN/Cs nanofiber FTIR spectra are close to those in the spectrum of PAN nanofiber. The peak detected at $3625 \mathrm{~cm}^{-1}$ is attributed to the $\mathrm{N}-\mathrm{H}$ stretching of the amine groups of the chitosan confirm the overlay. The peak of $\mathrm{O}-\mathrm{H}$ bending of chitosan shifted slightly from 1620 to $1627 \mathrm{~cm}^{-1}$. The peaks near $2900 \mathrm{~cm}^{-1}$, attributed to ethylene, do not shift much.

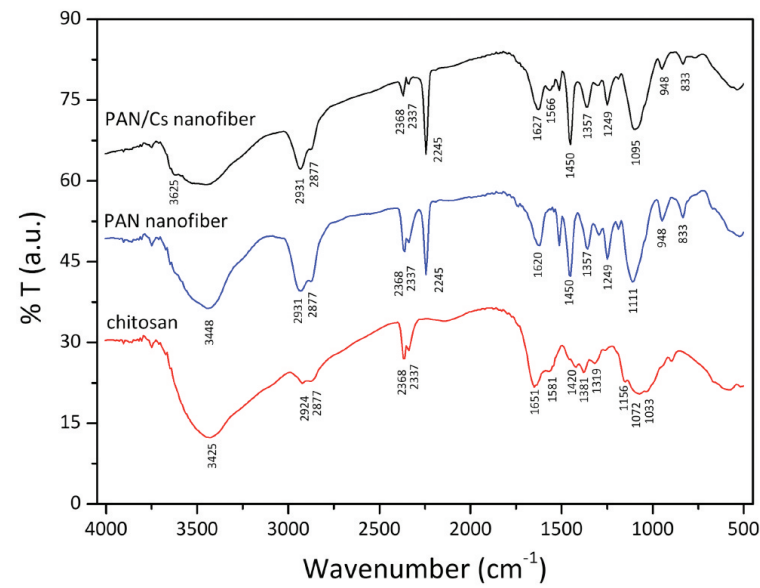

FIGURE 3. FTIR spectra of chitosan, PAN nanofiber, and PAN/Cs nanofiber

\section{SAFROLE SENSING PROFILE}

Figure 4(a) shows the frequency response of the asprepared QCM sensor to safrole vapor. The safrole concentration was varied between 0.3 and $6 \mathrm{mg} \mathrm{L}^{-1}$. Upon safrole injection into the sensing chamber, the frequency shifts sharply in the first few seconds and becomes steady after about $120 \mathrm{~s}$. The PAN nanofiber QCM sensor produces shifts of $1.5,3,8,17$, and $33 \mathrm{~Hz}$ after being exposed to safrole at concentrations of $0.3,0.6,1.2,3$, and $6 \mathrm{mg} \mathrm{L}^{-1}$, respectively. Meanwhile, the PAN/Cs nanofiber QCM sensor produces shift up to $8.5,14,25,60$, dan $113 \mathrm{~Hz}$ when exposed at a similar concentration. Upon being exposed to safrole at a concentration of $6 \mathrm{mg} \mathrm{L}^{-1}$, the PAN/Cs shows a frequency shift of $113 \mathrm{~Hz}$. At the same concentration, the PAN nanofiber sensor alone exhibits a frequency shift of only $33 \mathrm{~Hz}$. The PAN/Cs nanofiber sensor gives a frequency shift nearly 5-fold larger than that of Pan nanofiber. These results indicate that additionally coating the PAN nanofiber with chitosan improves the QCM response.

The response value of PAN nanofiber and PAN/Cs nanofiber sensor to safrole in the concentration range of 0.3 - $6 \mathrm{mg} \mathrm{L}^{-1}$ is displayed in Figure 4(b). The frequency change is linear with safrole concentration with a determination coefficient $\left(\mathrm{R}^{2}\right)$ of 0.999 for both PAN nanofiber and PAN/ Cs nanofiber. The sensitivity of the PAN nanofiber, as calculated from the slope of the plot of frequency shift versus safrole concentration, is $4.5 \mathrm{~Hz} \mathrm{mg}^{-1} \mathrm{~L}$. Meanwhile, the sensitivity of the PAN/Cs nanofiber is $18.7 \mathrm{~Hz} \mathrm{mg}^{-1} \mathrm{~L}$. The sensitivity of the PAN/Cs nanofiber sensor nearly 5 times higher than that of PAN nanofiber. The sensitivity of the QCM safrole sensor increases significantly after further overlay with chitosan.

The limit of detection (LOD) and the limit of quantification (LOQ) can be determined based on the standard deviation of blank measurements and the slope of the plot of the frequency shift versus analyte concentration of Figure 4(b) (Long \& Winefordner 1983). The LOD and LOQ may be expressed as $3.3 \mathrm{\sigma} / \mathrm{S}$ and $10 \sigma / \mathrm{S}$, respectively, where $\sigma$ is the standard deviation of the blank air measurement $(0.17 \mathrm{~Hz})$, and $\mathrm{S}$ is the slope of the calibration curve $\left(4.5 \mathrm{~Hz}\right.$ and $\left.18.7 \mathrm{~Hz} \mathrm{mg}^{-1} \mathrm{~L}\right)$. The calculated LOD and LOQ of PAN/Cs nanofiber sensor are found to be 0.03 and $0.09 \mathrm{mg} \mathrm{L}^{-1}$, respectively, while the previous study shows LOD of $1 \mathrm{mg} \mathrm{L}^{-1}$ (Rianjanu et al. 2018a).

Figure 5(a) shows the reproducibility of PAN and PAN/ Cs nanofiber as safrole sensors. When the response reaches equilibrium, the fresh dry ambient air was introduced to the detection chamber to flush any absorbed safrole until desorption was complete. The sensor was again exposed to the safrole vapor with the same concentration as before. It appears that the analyte adsorption-desorption cycles are reproducible. The frequency reading returns to its original value after purging the sensor chip with dry fresh air for both sensor chips. The sensing response was considerably reproducible after three consecutive sample injections. This is indicative that the QCM sensing system is reproducible for safrole vapor detection. 

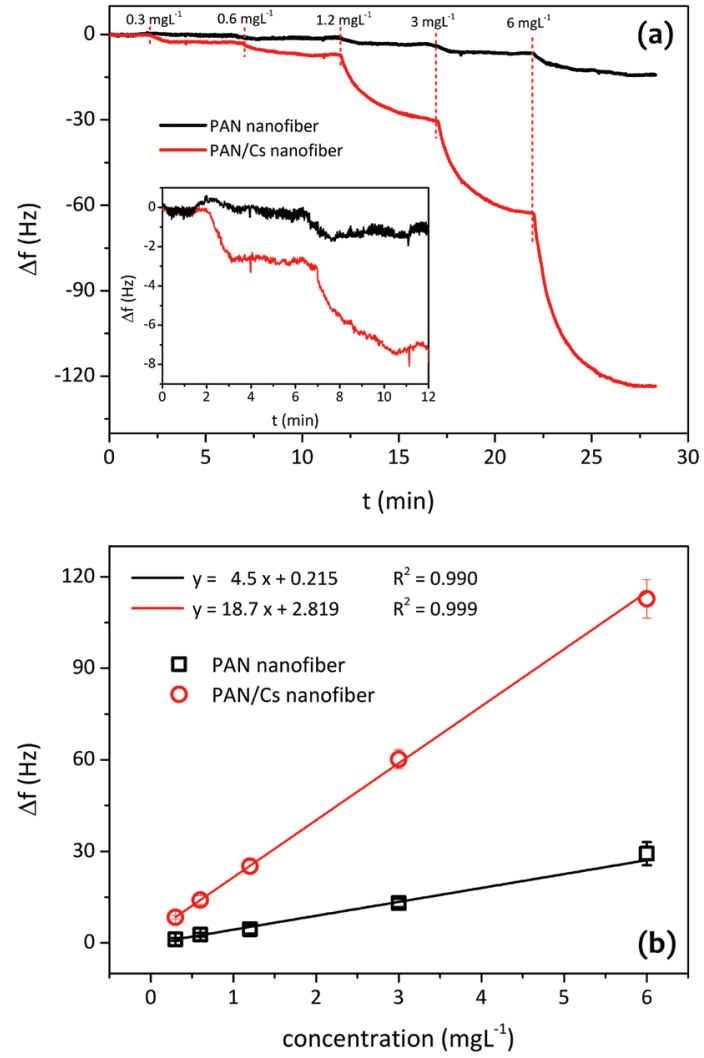

FIGURE 4. (a) Dynamic responses of QCM sensors upon exposure to increasing safrole concentrations, (b) Response of QCM sensors with various safrole concentrations. The linear fitting indicates the sensitivity of the sensors. Error bars were calculated by the standard deviation of 5 independent repeated measurements

To investigate the repeatability of the PAN and PAN/ Cs nanofiber sensor, the sensor was exposed repeatedly to safrole vapor at a fixed concentration of $1.2 \mathrm{mg} \mathrm{L}^{-1}$. When the QCM frequency reading reached equilibrium after each safrole injection, the prepared sensor was purged with dry ambient air to remove adsorbed safrole molecules. Figure 5(b) shows the QCM sensing repeatability test. The standard deviations for PAN and PAN/Cs nanofiber-based sensors were found to be $0.4 \mathrm{~Hz}$ and $1.7 \mathrm{~Hz}$, respectively. The small fluctuation in the frequency shift suggests that both QCM sensing chips show good repeatability. Moreover, the relative standard deviation (RSD) was calculated to be $8.2 \%$ and $7.5 \%$ for PAN nanofiber and PAN/Cs nanofiber sensor, respectively. The small relative standard deviation for PAN/Cs nanofiber sensor shows the chitosan-overlaid PAN film improved the sensor repeatability.

Figure 6 shows the frequency response of the PAN and PAN/Cs nanofiber sensor to safrole vapor at $1.2 \mathrm{mg} \mathrm{L}^{-1}$. It is fit for the first-order instrument response. The time constant $(\tau)$, defined as the time needed for an instrument to achieve $63.2 \%$ of its maximum response value, is 35 and $51 \mathrm{~s}$ for PAN nanofiber and PAN/Cs nanofiber sensor, respectively. It is shown that PAN nanofiber overlay with chitosan exhibit faster time constant than that of PAN nanofiber. It also confirms the improvement of sensing performance after chitosan overlay. The instrument response time must be
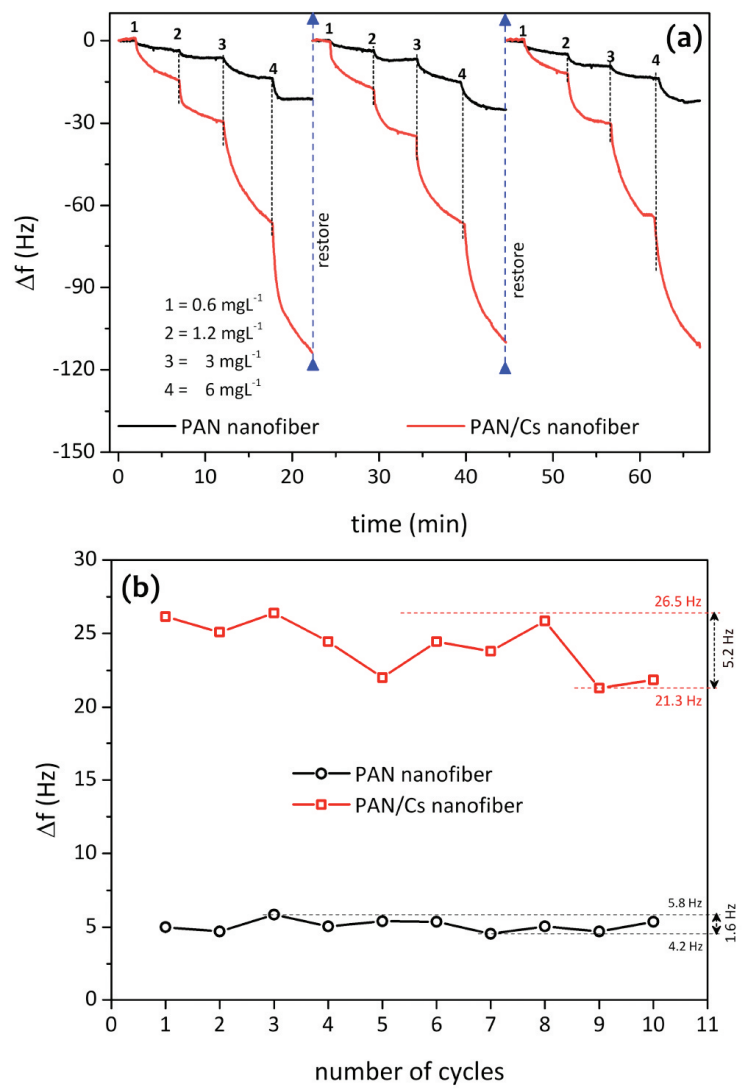

FIGURE 5. (a) Reproducibility and (b) repeatability test of PAN and PAN/Cs nanofiber sensor underexposure of $1.2 \mathrm{mg} \mathrm{L}^{-1}$ safrole vapor

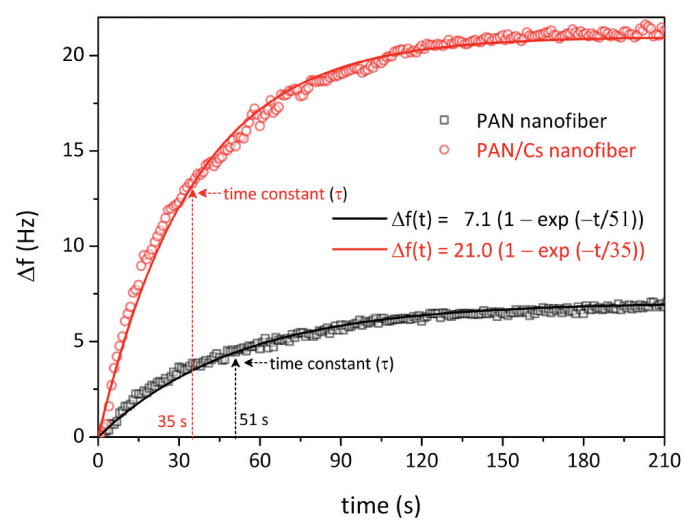

FIGURE 6. Time response of PAN and PAN/Cs nanofiber sensors upon exposure to $1.2 \mathrm{mg} \mathrm{L}^{-1}$ safrole

short for the rapid detection of the analyte. Our previous study (Rianjanu et al. 2018a) on safrole detection by QCM showed a response time of about $300 \mathrm{~s}$.

Long-term stability is important for the applications of gas sensors. The PAN and PAN/Cs nanofiber sensors were regularly tested with $1.2 \mathrm{mg} \mathrm{L}^{-1}$ safrole vapor for 30 days to evaluate their long-term stability. During this period, each QCM chip was used to measure the analyte once every 5 days. Figure 7 displays the frequency shift as a function of time over 30 days. The first response is relatively stable 


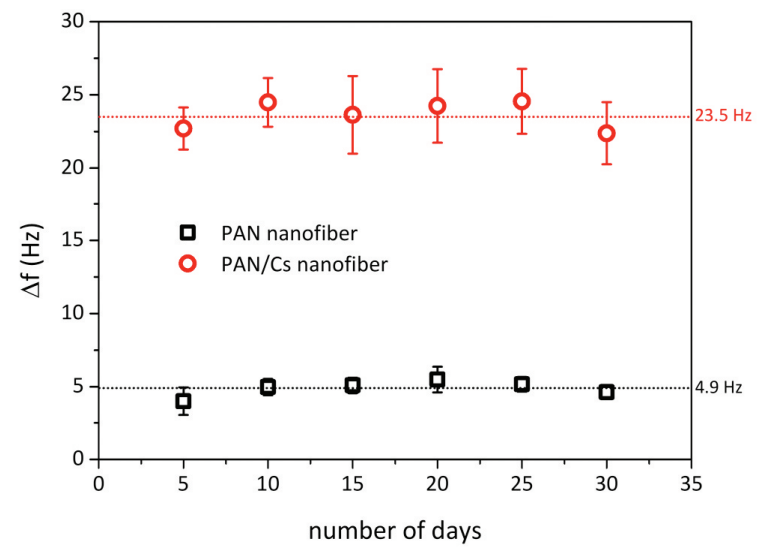

FIGURE 7. Long-term stability of the PAN and PAN/Cs nanofiber sensor upon exposure to $1.2 \mathrm{mg} \mathrm{L}^{-1}$ safrole for 30 days

after 30 days of measurement for the QCM chips, indicating the long-term stability of the QCM system. The maximum frequency fluctuation is about $0.9 \mathrm{~Hz}(15 \%)$ and $2.6 \mathrm{~Hz}$ $(11 \%)$ for PAN nanofiber and PAN/Cs nanofiber sensor, respectively. The result indicates improved long-term stability after chitosan overlay.

The PAN/Cs nanofiber sensing system towards $1.2 \mathrm{mg}$ $\mathrm{L}^{-1}$ of various VOC gases, which usually present in the air (US EPA), was investigated, and the results are shown in Figure 8 . The highest frequency shift has been observed as $25.66 \mathrm{~Hz}$ for safrole sample. The other frequencies shifts were observed much lower compared to that of safrole. Thus, it can be concluded that the PAN/Cs nanofiber sensor showed an excellent response to safrole vapor.

\section{THE PROPOSED GAS SENSING MECHANISM}

Based on the safrole sensing properties of the PAN/Cs nanofiber, we believe that the nanostructured nature of the sensing surface is critical. The porous structure of the PAN/Cs nanofiber is advantageous to achieve quick and

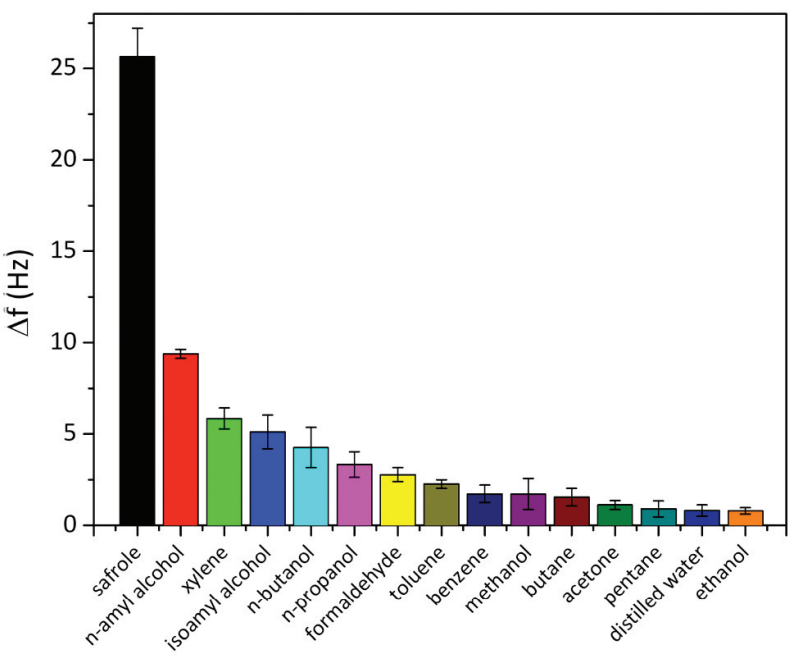

FIGURE 8. The frequency response of PAN/Cs nanofiber-based QCM sensor upon exposure to $1.2 \mathrm{mg} \mathrm{L}^{-1}$ of various VOCs

large frequency responses. The analyte vapor is effectively diffused into the nanofibers. A large frequency shift serves as evidence of a strong interaction between nanofibers and analytes. We believe that the intermolecular forces between the nanofibers at the QCM electrode surface and safrole are the major contributors to the frequency response.

Figure 9 depicts the proposed intermolecular interactions between PAN/Cs nanofiber and safrole vapor. Each chitosan subunit has an amine group that contains a nitrogen atom. This nitrogen atom has one lone pair of electrons and can act as a Lewis base. As proposed in the previous study (Rianjanu et al. 2018a) the frequency shift is due to a strong hydrogen bond between the hydrogen atoms of safrole and the nitrogen atom at the chitosan subunit. The two hydrogen atoms located between two oxygen atoms in the safrole structure will be electron-deficient, thus behaving as Lewis acids. The significant frequency changes caused by the strong intermolecular bonding between the

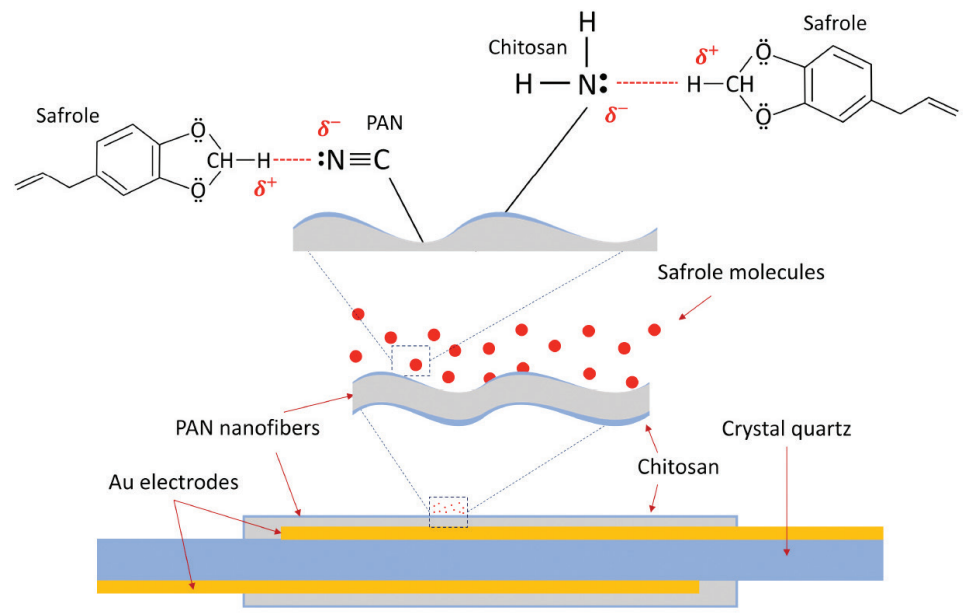

FIGURE 9. Schematic illustration of probable safrole sensing mechanism by PAN/Cs nanofiber-based sensor 
nitrogen and hydrogen atoms. Other weak intermolecular interaction such as hydrophobic-hydrophilic, dipoledipole, and $\pi-\pi$ interactions may also occur. Moreover, other tested VOCs shows weaker intermolecular interaction compared to safrole, indicate by lower frequency changes (Figure 8).

The other possibilities are that the chitosan does not adequately cover the PAN nanofiber surface. Part of the PAN fibers may interact with safrole by intermolecular force as we reported earlier (Rianjanu et al. 2018a). However, the chitosan fibers still have a significant contribution to the sensing interactions. The nanofibrous structure of both PAN and PAN/Cs nanofiber provides a much high surface area. Moreover, when the PAN nanofibers are overlaid with chitosan, the chitosan molecules cover the PAN nanofiber surface. Chitosan with a significant number of amine groups will interact with safrole by intermolecular interaction. The high surface area of the nanofibers and strong chitosansafrole intermolecular force is believed to contribute to the increased sensitivity of the PAN/Cs nanofiber sensor. The PAN nanofibers alone can also interact directly with safrole molecule via charge transfer mechanism through their nitrile groups and the safrole's hydrogen atoms that are sandwiched in between two ether groups (Rianjanu et al. 2018a). When the PAN nanofibers are coated with chitosan, the nitrile groups are less accessible to safrole anymore. It means that PAN is needed to give a nanofibrous coating with the large surface area.

\section{CONCLUSION}

Electrospinning and drop-casting methods were used to create a PAN/Cs nanofiber-based QCM sensor for safrole analysis. The 3D structure of the PAN and PAN/Cs nanofibers leads to a good response to safrole. Moreover, the QCM modified with PAN nanofibers overlay with chitosan gives a better response to safrole vapor detection compared to PAN nanofiber alone. The others sensing performance, including the sensitivity, repeatability, time constant, and long-term stability, also shows an improvement when the PAN nanofiber sensor overlay with chitosan. The large response of the QCM was due to the interaction between chitosan's amine group and safrole through intermolecular hydrogen bonding. It could be very promising for the routine detection of safrole. The QCM sensing chip modified with electrospun polymers may offer a new strategy for real-time sensing methods for precursors of drugs, especially MDMA and other ATS derivatives.

\section{ACKNOWLEDGEMENTS}

This research and APC were funded by the Ministry of Research, Technology and Higher Education of the Republic of Indonesia through a research scheme of Penelitian Terapan (contract number 2833/UN1.DITLIT/ DIT-LIT/LT/2019). A. Rianjanu acknowledges a PhD. scholarship issued by the Ministry of Research, Technology and Higher Education of the Republic of Indonesia through
PMDSU program. We also thank Mr. Budiarto (Indonesian National Police, Headquarters, Jakarta) for supplying the safrole samples. We declare that there are no conflicts of interests.

\section{REFERENCES}

Aba, L., Yusuf, Y., Mitrayana, Siswanta, D., Junaidi. \& Triyana, K. 2014. Sensitivity improvement of ammonia gas sensor based on poly (3, 4-ethylenedioxythiophene): Poly (strenesulfonate) by employing doping of bromocresol green. Journal of Nanotechnology 2014: 864274.

Ayad, M.M. \& Minisy, I.M. 2016. Detection and kinetics of methylamine on chitosan film coated quartz crystal microbalance electrode. Progress in Organic Coatings 100: 76-80.

Ayad, M.M., Salahuddin, N.A., Minisy, I.M. \& Amer, W.A. 2014. Chitosan/polyaniline nanofibers coating on the quartz crystal microbalance electrode for gas sensing. Sensors and Actuators B: Chemical 202: 144-153.

Chotimah, C., Rianjanu, A., Winardianto, B., Munir, M., Kartini, I. \& Triyana, K. 2016. Electrical conductivity improvement of polyvinyl alcohol nanofiber by solvent vapour treatment. International Journal on Advanced Science, Engineering and Information Technology 6(5): 675.

Cipriani, E., Zanetti, M., Bracco, P., Brunella, V., Luda, M.P. \& Costa, L. 2016. Crosslinking and carbonization processes in PAN films and nanofibers. Polymer Degradation and Stability 123: $178-188$

Ding, B., Wang, M., Wang, X., Yu, J. \& Sun, G. 2010. Electrospun nanomaterials for ultrasensitive sensors. Materials Today 13(11): 16-27.

Evyapan, M., Kadem, B., Basova, T.V., Yushina, I.V. \& Hassan, A.K. 2016. Study of the sensor response of spun metal phthalocyanine films to volatile organic vapors using surface plasmon resonance. Sensors Actuators B Chem. 236: 605-613.

Hackner, A., Legner, W., Müller, G., Biavardi, E., Dalcanale, E., Zampolli, S., Elmi, I. \& Cardinali, G.C. 2013. Surface ionization detection of amine containing drugs. Sensors and Actuators B: Chemical 185: 771-776.

He, K., Wang, X., Meng, X., Zheng, H. \& Suye, S.I. 2014. Amperometric determination of hydroquinone and catechol on gold electrode modified by direct electrodeposition of poly(3,4-ethylenedioxythiophene). Sensors and Actuators B: Chemical 193: 212-219.

Hernández, P.T., Naik, A.J.T., Newton, E.J., Hailes, S.M.V. \& Parkin, I.P. 2014. Assessing the potential of metal oxide semiconducting gas sensors for illicit drug detection markers. Journal of Materials Chemistry A 2(23): 8952-8960.

Hidayat, S.N., Julian, T., Rianjanu, A., Kusumaatmadja, A., Triyana, K. \& Roto, R. 2017. Quartz crystal microbalance coated by PAN nanofibers and PEDOT: PSS for humidity sensor. International Seminar on Sensors, Instrumentation, Measurement and Metrology (ISSIMM). pp. 119-123.

Honeychurch, K. 2016. Review: The application of liquid chromatography electrochemical detection for the determination of drugs of abuse. Separations 3(4): 28. doi:10.3390/separations3040028.

Huang, W., Wang, X., Jia, Y., Li, X., Zhu, Z., Li, Y., Si, Y., Ding, B., Wang, X. \& Yu, J. 2013. Highly sensitive formaldehyde sensors based on polyvinylamine modified polyacrylonitrile nanofibers. RSC Advances 3(45): 22994. 
Jia, Y., Yu, H., Cai, J., Li, Z. \& Dong, F. 2017. Explore on the quantitative analysis of specific surface area on sensitivity of polyacrylic acid-based QCM ammonia sensor. Sensors and Actuators B: Chemical 243: 1042-1045.

Jia, Y., Yu, H., Zhang, Y., Dong, F. \& Li, Z. 2016. Cellulose acetate nanofibers coated layer-by-layer with polyethylenimine and graphene oxide on a quartz crystal microbalance for use as a highly sensitive ammonia sensor. Colloids Surfaces $B$ Biointerfaces 148: 263-269.

Jia, Y., Yan, C., Yu, H., Chen, L. \& Dong, F. 2014. One-step fabrication of ammonia sensor by electrospinning PS-bPMA nanofibers on quartz crystal microbalance. Sensors and Actuators B: Chemical 203: 459-464.

Julian, T., Rianjanu, A., Hidayat, S.N., Kusumaatmaja, A., Roto, R. \& Triyana, K. 2019. Quartz crystal microbalance coated with PEDOT-PSS/PVA nanofiber for a high-performance humidity sensor. Journal of Sensors and Sensor Systems 8(2): 243-250

Kakida, H. \& Tashiro, K. 1997. Mechanism and kinetics of stabilization reaction of polyacrylonitrile and related copolymers II. Relationships between isothermal DSC thermograms and FT-IR spectral changes of polyacrylonitrile in comparison with the case of acrylonitrile/methacrylic acid. Polymer Journal 29(4): 353-357.

Kim, S.S.\& Lee, J. 2014. Antibacterial activity of polyacrylonitrilechitosan electrospun nanofibers. Carbohydrate Polymers 102(1): 231-237.

Li, J., Su, S., Zhou, L., Kundrát, V., Abbot, A.M., Mushtaq, F., Ouyang, D., James, D., Roberts, D. \& Ye, H. 2013. Carbon nanowalls grown by microwave plasma enhanced chemical vapor deposition during the carbonization of polyacrylonitrile fibers. Journal of Applied Physics 113(2): 024313.

Long, G.L. \& Winefordner, J.D. 1983. Limit of detection: A closer look at the IUPAC definition. Analytical Chemistry 55(7): 712A-724A.

Lu, H.L., Lu, C.J., Tian, W.C. \& Sheen, H.J. 2015. A vapor response mechanism study of surface-modified single-walled carbon nanotubes coated chemiresistors and quartz crystal microbalance sensor arrays. Talanta 131: 467-474.

Mahendra, B., Nugroho, F. \& Yusuf, Y. 2018. Low-frequency electrohydrodynamic convection patterns in nematic liquid crystal aligned using parallel-oriented nanofiber. Japanese Journal of Applied Physics 57(2): 021701.

Pinalli, R., Barboza, T., Bianchi, F., Massera, C., Ugozzoli, F. \& Dalcanale, E. 2013. Detection of amphetamine precursors with quinoxaline-bridged cavitands. Supramolecular Chemistry 25(9-11): 682-687.

Portaccio, M., Menale, C., Diano, N., Serri, C., Mita, D.G. \& Lepore, M. 2015. Monitoring production process of cisplatinloaded PLGA nanoparticles by FT-IR microspectroscopy and univariate data analysis. Journal of Applied Polymer Science 132(3): 1-9. https://doi.org/10.1002/app.41305.

Rianjanu, A., Nugroho, D.B., Kusumaatmaja, A., Roto, R. \& Triyana, K. 2019a. A study of quartz crystal microbalance modified with polyvinyl acetate nanofiber to differentiate short-chain alcohol isomers. Sensing and Bio-Sensing Research 25: 100294.

Rianjanu, A., Hasanah, S.A., Nugroho, D.B., Kusumaatmaja, A., Roto, R. \& Triyana, K. 2019b. Polyvinyl acetate film-based quartz crystal microbalance for the detection of benzene, toluene, and xylene vapors in air. Chemosensors 7(2): 20. doi:10.3390/chemosensors7020020.
Rianjanu, A., Roto, R., Julian, T., Hidayat, S .N., Kusumaatmaja, A., Suyono, E.A. \& Triyana, K. 2018a. Polyacrylonitrile nanofiber-based quartz crystal microbalance for sensitive detection of safrole. Sensors 18(4): 1150.

Rianjanu, A., Julian, T., Hidayat, S.N., Suyono, E.A., Kusumaatmaja, A. \& Triyana, K. 2018b. Polyacrylonitrile nanofiber as polar solvent $\mathrm{N}, \mathrm{N}$-dimethyl formamide sensor based on quartz crystal microbalance technique. Journal of Physics: Conference Series 1011(1): 012067.

Rianjanu, A., Kusumaatmaja, A., Suyono, E.A. \& Triyana, K. 2018c. Solvent vapor treatment improves mechanical strength of electrospun polyvinyl alcohol nanofibers. Heliyon 4(4): e00592.

Rianjanu, A., Hidayat, S.N., Julian, T., Suyono, E.A., Kusumaatmaja,A. \& Triyana, K. 2018d. Swelling behavior in solvent vapor sensing based on Quartz Crystal Microbalance (QCM) Coated Polyacrylonitrile (PAN) nanofiber. IOP Conference Series: Materials Science and Engineering 367: 012020.

Saito, K., Saito, R., Kikuchi, Y., Iwasaki, Y., Ito, R. \& Nakazawa, H. 2011. Analysis of drugs of abuse in biological specimens. Journal of Health Science 57(6): 472-487.

Sauerbrey, G. 1959. Verwendung von Schwingquarzen zur Wägung dünner Schichten und zur Mikrowägung. Zeitschrift für Phys. 155(2): 206-222.

Singer, M. 2008. Drugs and development: The global impact of drug use and trafficking on social and economic development. International Journal of Drug Policy 19(6): 467-478.

Siow, K.S., Britcher, L., Kumar, S. \& Griesser, H.J. 2019. QCM-D and XPS study of protein adsorption on plasma polymers with sulfonate and phosphonate surface groups. Colloids Surfaces B Biointerfaces 173(April 2018): 447-453.

Sun, Y.F., Liu, S.B., Meng, F.L., Liu, J.Y., Jin, Z., Kong, L.T. \& Liu, J.H. 2012. metal oxide nanostructures and their gas sensing properties: A review. Sensors 12(12): 2610-2631.

Triyana, K., Sembiring, A., Rianjanu, A., Hidayat, S., Riowirawan, R., Julian, T., Kusumaatmaja, A., Santoso, I. \& Roto, R. 2018. Chitosan-based quartz crystal microbalance for alcohol sensing. Electronics 7(9): 181.

United Nations Office on Drugs and Crime. 2017. Global Overview of Drug Demand and Supply, Vienna. https://www. unodc.org/wdr2017/field/Booklet_2_HEALTH.pdf.

Wang, J., He, E., Liu, X., Yu, L., Wang, H., Zhang, R. \& Zhang, H. 2017. High performance hydrazine vapor sensor based on redox mechanism of twisted perylene diimide derivative with lower reduction potential. Sensors and Actuators B: Chemical 239: 898-905.

Wang, N., Wang, X., Jia, Y., Li, X., Yu, J. \& Ding, B. 2014. Electrospun nanofibrous chitosan membranes modified with polyethyleneimine for formaldehyde detection. Carbohydrate Polymers 108(1): 192-199.

Wang, S.Y., Ma, J.Y., Li, Z.J., Su, H.Q., Alkurd, N.R., Zhou, W.L., Wang, L., Du, B., Tang, Y.L., Ao, D.Y.,Zhang, S.C., Yu, Q.K \& Zu, X.T. 2015. Surface acoustic wave ammonia sensor based on $\mathrm{ZnO} / \mathrm{SiO} 2$ composite film. Journal of Hazardous Materials 285: 368-374.

Xue, Y., Liu, J., Lian, F. \& Liang, J. 2013. Effect of the oxygeninduced modification of polyacrylonitrile fibers during thermal-oxidative stabilization on the radial microcrystalline structure of the resulting carbon fibers. Polymer Degradation and Stability 98(11): 2259-2267.

Zhang, D., Wang, D., Li, P., Zhou, X., Zong, X. \& Dong, G. 2018. Facile fabrication of high-performance QCM humidity 
sensor based on layer-by-layer self-assembled polyaniline/ graphene oxide nanocomposite film. Sensors and Actuators B: Chemical 255: 1869-1877.

Zhang, K., Fan, G., Hu, R. \& Li, G. 2015. Enhanced dibutyl phthalate sensing performance of a quartz crystal microbalance coated with $\mathrm{Au}$-decorated $\mathrm{ZnO}$ porous microspheres. Sensors 15(9): 21153-21168

Zhang, K., Hu, R., Fan, G. \& Li, G. 2017. Graphene oxide/ chitosan nanocomposite coated quartz crystal microbalance sensor for detection of amine vapors. Sensors and Actuators B: Chemical 243: 721-730.

Aditya Rianjanu, Kuwat Triyana, Novalia Nurbaiti, Siti Astuti Hasanah \& Ahmad Kusumaatmaja

Department of Physics

Faculty of Mathematics and Natural Sciences

Universitas Gadjah Mada, Sekip Utara BLS 21

Yogyakarta 55281

Indonesia
Kuwat Triyana*

Institute of Halal Industry and System (IHIS)

Universitas Gadjah Mada, Sekip Utara

Yogyakarta 55281

Indonesia

Roto Roto

Department of Chemistry

Faculty of Mathematics and Natural Sciences

Universitas Gadjah Mada, Sekip Utara BLS 21

Yogyakarta 55281

Indonesia

*Corresponding author; email: triyana@ugm.ac.id

Received: 29 March 2019

Accepted: 20 July 2019 